\title{
Internet, Economic Growth and Recession
}

\author{
Shan-Ying Chu \\ Chung Yuan Christian University, Chung Li, Taiwan \\ Email: sychu@cycu.edu.tw
}

Received December 30, 2012; revised January 30, 2013; accepted February 19, 2013

\begin{abstract}
This paper investigates the impact of internet on economic growth and this impact during the recession. The data are drawn from World Bank in a panel of 201 countries from 1988 to 2010. Results from an OLS model reveal that a 10 percentage point increase in internet penetration rate raises real GDP per capita by 0.57 to 0.63 percentage points. During the recession relative to expansion, the coefficient of internet reduces but it still remains statistically positive. This suggests that internet provides a way to solve the problem of economic recession. Our results are robust to the inclusion of time and country fixed effects.
\end{abstract}

Keywords: Internet; Economic Growth; Recession

\section{Introduction}

In macroeconomics, the recession refers to the period of stagnation or negative growth in an economy's gross domestic product (GDP). In order to get rid of the recession, many economists suggest policies of stimulating aggregate demand following Keynes's macroeconomics theory or some other monetary policies. However, in addition to these policies, internet may play a useful role in leading the growth of economy or productivity which is evident in the literature but rarely studied on the topic of recession. Accordingly, this paper investigates the relationship between internet and economic growth and further examines it, especially during the recession. Our examination suggests that internet provides stimulus to economic growth and hence solves the problem of economic recession.

This paper uses data from World Bank in a panel of 201 countries from 1998 to 2010 with 1226 observations. Following Czernich et al., (2011) [1], a macroeconomic production function with constant returns to scale is built up. In addition to traditional inputs, we add internet penetration rate and an interaction term between it and a recession dummy. These added variables enable us to examine the impact of internet on economic growth as well as the impact during the recession. We also create models specific to economy expansion as well as to economy recession. The remainder of this article is organized as follows. Section 2 reviews related literature on internet and economic growth. Section 3 introduces theoretical and empirical framework and explains data and variables. Section 4 summarizes empirical results. Section 5 concludes and proposes suggestions.

\section{Literature on Internet and Economic Growth}

Internet positively impacts the economy since it spreads information, stimulates innovation, builds up network, fosters business, deepens capital, improves labor market, strengthens market competition, and helps firms to profit from emerging markets. Therefore, internet may help to fight against economic downturn. We review the literature mentioning the causality between internet and economic growth as follows.

Internet facilitates access to information and reduces search costs. Firms adopting internet are able to communicate better, faster and at lower costs. This reduces internal as well as external transaction costs and thus lowers production costs and enhances productivity and generates economic growth (Harris, 1998) [2]. Spread or spillover of knowledge across firms, regions, and countries provides a channel by which information technology in general results in significant productivity growth. This is because that the development of information technologies fundamentally improves the processing of information and hence promotes economic growth. Internet can be regarded as one of the information technologies and a truly general purpose technology (GPT) which is defined as technologies characterized by pervasiveness, inherent potential for technical improvements, and innovation complementarities. GPT can lead to externalities as knowledge spillovers (Bresnahan and Trajtenberg, 1995) [3]. In this respect, internet facilitates the spatial distribution of large batches of information that previously had to be collocated (Bloom et al., 2011) [4]. It also fosters cheaper information dissemination which enhances the adoption 
of new technologies devised by others (Benhabib and Spiegel, 2005) [5]. Internet affects the labor market (Stevenson, 2009) [6] and the product market (Levin, 2011) [7] and economic growth turns out to be positively related with the use of internet (Romer, 1990) [8]. In a nutshell, internet may settle the recession via spreading information, reducing transaction costs and then improving economic outcomes.

Internet deepens innovative capacities and capital, which is crucial for economic growth. Internet may affect the innovative capacities of the economy through development of new products, processes and business models to promote growth (Benhabib and Spiegel, 2005) [3]. Being one of information communication technologies (ICT), internet affects the growth performance through capital deepening. Internet has a direct effect on capital deepening through the rapid technological progress which leads to lower quality-adjusted prices and increasing output (Oliner and Sichel, 2002) [9]. In addition, internet is one of significant components of entrepreneurship capital which advances economic growth, and entrepreneurship capital is defined as the capacity for economic agents to generate new information (Audretsch and Keilbach, 2007) [10]. Therefore, internet can boost the economy from the recession through innovative capacities and entrepreneurship capital deepening.

Internet builds up network which enhances economic growth. It is a form of network capital with the ability to improve overall productivity across different sectors in the economy (Moshiri and Nikpour, 2010) [11]. As a network capital, internet has network effects implying that the more users adopt it, the more benefits that would accrue to existing internet users without the latter bearing extra costs. The emergence of the internet economy is a Schumpeterian event as a growth enhancing innovation (DePrince and Ford, 1999) [12]. Moreover, internet communication provides social networking which is advantageous for economic outcomes especially in fostering innovation (Granovetter, 2005) [13]. Since internet develops network and enhances innovative growth, it is expected to provide a solution for recession.

Internet fosters business and hence results in economic growth. Internet is utilized to reach new markets, learn new techniques through shared experiences and develop more resilient supply chains (Parikh et al., 2007) [14]. One of the potential economic benefits of widespread diffusion of internet access is to profit firms from providing goods and services to emerging markets. Internet has effects on organization, management, and human capital (Moshiri and Nikpour, 2010) [11]. It can increase effective governance (Kalathil, 2003) [15] and stronger institutions can lead to positive economic outcomes (Acemoglu et al., 2001) [16]. Moreover, high-speed internet allows for new business models, entrepreneurial activities and the collaboration of firms producing specialized inputs (Bloom et al., 2011) [4]. It increases trade, and accordingly it increases income growth through trade (Davies and Quinlivan, 2006) [17]. Subsequently, internet stirs up business and trade development which benefits the economy to grow and depart from recession.

Internet improves labor market and economic outcomes. High-speed internet helps better job matching (Bloom et al., 2011) [4]. In this way, internet has changed the way workers search for jobs, which has consequences for economy-wide productivity (Stevenson, 2009) [6]. In addition, internet strengthens market competition and leads the economy to grow. High-speed internet leads to lower entry barriers and higher market transparency (Bloom et al., 2011) [4] since it helps to remove information asymmetries and hence has the potential to make markets more competitive (Goel and Hsieh, 2002) [18]. With increasing access to information and increasing competition, markets become more efficient due to reduced pricedispersion and increased producer and consumer surplus (Jensen, 2007) [19]. Furthermore, Mishra and Newhouse (2009) [20] find that internet likely has positive effects on health outcomes that may affect economic development or growth in countries with immature heath care systems. To sum up, internet can solve the problem of recession through labor market improvement and market competition strengthening.

\section{Theoretical and Empirical Framework}

Internet plays a great role in spreading information. Endogenous growth proposed by Romer (1990) [8] figures out that growth is positively influenced by knowledge spillover. Therefore, economic growth is expected to be positively associated with internet. Following Czernich et al. (2011) [1], real gross domestic product (GDP) per capita is modeled as a function of labor, physical capital, human capital, and the technology state. In addition, we add one interaction term between internet and a recession dummy to investigate the influence of internet on economic growth during the recession. Moreover, we add time and country specific dummy variables to control for year and country fixed effects.

A simple macroeconomic production function with constant returns to scale and aforementioned variables is formulated by a reduced form as

$$
Y_{i t}=A_{i t} F\left(L_{i t}, K_{i t}, H_{i t}\right)
$$

Here, subscript $i$ stands for country while $\mathrm{t}$ means year. $Y_{i t}$ means real gross domestic product (GDP) per capita, $A_{i t}$ reveals the technology state, $L_{i t}$ represents labor, $K_{i t}$ is physical capital and $H_{i t}$ means human capital. We take a logarithm form to transform Equation (1) into Equation (2) as below. 
$\log Y_{i t}=\log A_{i t}+\alpha_{2} \log L_{i t}+\alpha_{3} \log K_{i t}+\alpha_{4} \log H_{i t}+\varepsilon_{i t}$

where $\alpha_{2}$ to $\alpha_{4}$ are parameters to be estimated. $\varepsilon_{i t}$ is an error term. Assume that technology state evolves along an exponential growth path over time with a growth parameter, $\lambda_{i}$, which is specific to a country $i$ 's technological progress. Therefore, we can rewrite $A_{i t}$ as

$$
A_{i t}=A_{0} e^{\lambda i t}
$$

Since internet helps to generate and spread information, $\lambda_{i}$ is expected to be affected by internet. The technological growth parameter can be specified a $\mathrm{s}$ a function of internet as

$$
\lambda_{i} t=\alpha_{t}+\alpha_{1} \log I_{i t}
$$

where $I_{i t}$ represents internet usage for country $i$ in year $t$ and $\alpha_{t}$ captures time specific effects. We integrate Equations (2)-(4). In addition, in order to investigate the relationship between economic growth with internet as well as recession, an interaction term between internet and recession dummy, $R$, is set. Subsequently, we build up a complete regression framework as

$$
\begin{aligned}
\log Y_{i t}= & \alpha_{i}+\alpha_{t}+\alpha_{1} \log I_{i t}+\alpha_{2} \log L_{i t}+\alpha_{3} \log K_{i t} \\
& +\alpha_{4} \log H_{i t}+\alpha_{5} \log I_{i t} * R_{i t}+\varepsilon_{i t}
\end{aligned}
$$

Here $Y_{i t}$ representing real GDP per capita is expressed in 1998 purchasing power parity. In order to capture country-specific and year-specific effects, $\alpha_{i}$ and $\alpha_{t}$ which are separately composed of a set of country and year dummies are integrated into the model.

The term $I_{i t}$ capturing technology state in an economy is measured by internet penetration rate which is the number of internet users per 100 population. $L_{i t}$ representing labor inputs is measured by the labor participation rate. $K_{i t}$ meaning physical capital is proxied by the ratio of real fixed capital formation to real GDP. $H_{i t}$ standing for human capital is captured by secondary education gross enrollment rate. $R_{i t}$ is a dummy variable with value equal to 1 representing recession and 0 otherwise.

The effect of internet on real GDP per capita can be estimated by $\alpha_{1}$ and $\alpha_{5}$ while $R_{i t}=1$ is specific to the recession. We can realize how internet affects economic growth during the recession by summing up $\alpha_{1}$ and $\alpha_{5}$.

Our data collected form World Bank are unbalanced panel data composed of 201 countries and 13 years from 1988 to 2010. GDP per capita is gross domestic product divided by midyear population. It is the sum of gross value added by all resident producers in the economy plus any product taxes and minus any subsidies not included in the value of the products. It is calculated in US dollars. Countries under consideration are composed of four different levels of income: low, lower-middle, upper-middle and high. The mean GDP per capita for each level separately are $1560,5844,12,876$, and 20,533. There are 1226 observations in our study and $18 \%$ of them are in the recession. Summary statistics of variables are tabulated in Table 1.

\section{Empirical Results}

Empirical model represented by Equation (5) in the above Section is estimated based on an ordinary least squares (OLS) technique. Estimation results are demonstrated in Table 2. Since variables are taken in a logarithm form, the coefficient of a variable represents the ratio between the percentage change in real GDP per capita, that is economic growth, and the percentage change in the corresponding variable. In other words, the coefficient means the elasticity.

Model 1 uses the whole sample of 1266 observations. A positive relationship between internet and economic

\begin{tabular}{|c|c|c|c|c|c|}
\hline Var. & Explanation & Mean & Std.Dev. & Min & Max \\
\hline$Y_{i t}$ & Real GDP per capita & 13272.54 & 13332.72 & 249.20 & 74113.94 \\
\hline$I_{i t}$ & $\begin{array}{c}\text { Internet penetration } \\
\text { rate }(\%)\end{array}$ & 21.72 & 24.39 & 0.00 & 92.18 \\
\hline$L_{i t}$ & $\begin{array}{c}\text { Labor participation } \\
\text { rate }(\%)\end{array}$ & 51.37 & 15.07 & 10.50 & 88.80 \\
\hline$K_{i t}$ & $\begin{array}{c}\text { Real fixed capital } \\
\text { formation to real GDP }\end{array}$ & 6350.32 & 8135.51 & 10 & 56546 \\
\hline$H_{i t}$ & $\begin{array}{l}\text { Secondary education } \\
\text { gross enrollment } \\
\text { rate }(\%)\end{array}$ & 76.55 & 29.88 & 5.19 & 162.35 \\
\hline$R_{i t}$ & Recession dummy & 0.18 & 0.39 & 0 & 1 \\
\hline
\end{tabular}
growth is evidently consistent with findings in the literature. Results from an OLS model reveals that a 10-percen-

Table 1. Summary statistics.

Table 2. Internet, recession and real GDP per capita

\begin{tabular}{cccc}
\hline $\begin{array}{c}\text { Dependent variable: Log } \\
\text { of real GDP per capita }\end{array}$ & Model 1 & Model 2 & Model 3 \\
\hline Log of internet penetration rate & $0.063^{* * *}$ & $0.059^{* * *}$ & $0.057^{* *}$ \\
& $(0.01)$ & $(0.03)$ & $(0.01)$ \\
Log of labor participation rate & $0.477^{* * *}$ & $0.508^{* * *}$ & $0.470^{* * *}$ \\
& $(0.02)$ & $(0.06)$ & $(0.03)$ \\
Log of real fixed capital & $0.620^{* * *}$ & $0.646^{* * *}$ & $0.610^{* * *}$ \\
formation to real GDP & $(0.01)$ & $(0.02)$ & $(0.01)$ \\
Log of secondary education & $0.321^{* * *}$ & $0.183^{* * *}$ & $0.351^{* *}$ \\
gross enrollment rate & $(0.02)$ & $(0.07)$ & $(0.02)$ \\
Log of internet penetrate & $-0.011^{*}$ & & \\
ration * Recession dummy & $(0.01)$ & & \\
Constant & $0.841^{* * *}$ & $0.798^{* * *}$ & $1.171^{* * *}$ \\
Country dummies & $(0.169)$ & $(0.185)$ & $(0.455)$ \\
Year dummies & Yes & Yes & Yes \\
$R$-squared & Yes & Yes & Yes \\
Number of observations & 1266 & 1036 & 230 \\
\hline
\end{tabular}

Note: ${ }^{*},{ }^{* *},{ }^{* * *}$ separately represent that the coefficient is significant at $10 \%$, $5 \%, 1 \%$ significance level. 
tage point increase in internet penetration rate raises real GDP per capita by 0.63 percentage points when the economy is not in the recession. The coefficient of the interaction term between internet penetration rate and recession dummy is negative $(-0.011)$ and, at a $10 \%$ significance level, it rejects the null hypothesis that the impact of internet on economic growth keeps identical regardless of the economy is in the recession or not. That is, during the recession, the marginal effect of log of internet penetration rate reduces by 0.011 . However, adding the coefficient of log of internet penetration rate $(0.063)$ and that of the interaction term $(-0.011)$, we still obtain a positive relationship $(0.063-0.011=0.052)$ between internet and economic growth during the recession. In other words, a 10-percentage point increase in internet penetration rate raises real GDP per capita by 0.52 percentage points when the economy is in the recession. Therefore, internet still provides a possible way to stimulate real GDP per capita to grow during the recession. We accordingly suggest that some policies enhancing internet penetration rate should be taken in order to solve the problem of the recession.

Since Model 1 supports that the impact of internet on economic growth varies across economy cycle, we subgroup data into two parts which separately produce estimation results of Model 2 for non-recession and Model 3 for recession. $R$-squared coefficients across Model 1 to Model 3 are all around 0.95 that means the explanation power of each model reaches $95 \%$. Year-specific and country-specific dummies are included in all models to control for time and country fixed effects. Almost all these coefficients are significant.

Model 2 utilizes 1036 observations when the economy is not in the recession while Model 3 utilizes 230 observations during the recession. Comparing estimation results, the coefficients of internet are both significantly positive in Models 2 and 3. However, it is smaller and less significant during the recession. This is likely due to network effects. Our data reveal that the internet penetration rate grows by $54 \%$ when the economy boosts; however, it increases only by $49 \%$ during the recession. Slower growth in the number of internet users during the recession makes the network increase slowly. Subsequently it results in slower information spreading across the network and hence a smaller impact of internet on economic growth is produced.

Moreover, the slower growth of internet use during the recession is possibly arisen from less sufficient ICT infrastructure. For instance, the broadband infrastructure grows by $247 \%$ when the economy boosts while it increases only by $75 \%$ during the recession.

\section{Conclusions and Suggestions}

Getting rid of recession is one of the most important po- licies of the government. In addition to traditional policy advices like stimulating aggregate demand, this paper proposes the recommendation of spreading the usage of internet, which has started quickly developing in recent two decades. We hence investigate the relationship between internet and economic growth and further examine this relationship during the recession. 1266 observations are drawn from World Bank in a panel of 201 countries from 1988 to 2010. Among them, 230 observations belong to the period of the recession. Results from an OLS model reveal that a 10 percentage point increase in internet penetration rate raises real GDP per capita by 59 percentage points when the economy boosts and by 57 percentage points during the recession, respectively. This suggests that internet is a useful tool to deal with the problem of economic recession. Our results are robust to the inclusion of time and country fixed effects.

Since a significantly positive impact of internet on economic growth during the recession is evident, we suggest that a country should increase internet penetration rate to get rid of economy recession. The government should stimulate ICT infrastructure, which can lead to more internet users and then increase real GDP per capita via network effects.

\section{Acknowledgements}

National Science Council supports this research. The project number is NSC 102-2918-I-033-001-.

\section{REFERENCES}

[1] N. Czernich1, O. Falck, T. Kretschmer and L. Woessmann, "Broadband Infrastructure and Economic Growth," The Economic Journal, Vol. 121, No. 552, 2011, pp. 505532.

[2] R. G. Harris, "The Internet as a GPT: Factor Market Implications,” NBER Working Papers: 13886, 1998.

[3] T. F. Bresnahan and M. Trajtenberg, "General Purpose Technologies: Engines of Growth," Journal of Econometrics, Vol. 65, No. 1, 1995, pp. 83-108. doi:10.1016/0304-4076(94)01598-T

[4] N. Bloom, T. Kretschmer and J. Van Reenen, "Are Family-Friendly Workplace practices a Valuable Firm Resource?" Strategic Management Journal, Vol. 32, No 4, 2011, pp. 343-367. doi:10.1002/smj.879

[5] J. Benhabib and M. M. Spiegel, "Human Capital and Technology Diffusion,” In: P. Aghion and S. Durlauf, Eds., Handbook of Economic Growth, Elsevier, Amsterdam, 2005.

[6] B. Stevenson, "The Internet and Job Search," In: D. Autor, Ed., Studies of Labour Market Intermediation, University of Chicago Press, Chicago, pp. 67-88.

[7] J. D. Levin, "The Economics of Internet Markets," NBER Working Papers: 16852, 1998.

[8] P. M. Romer, "Endogenous Technical Change," Journal 
of Political Economy, Vol. 98, No. 5, 1990, pp. S71-S101. doi:10.1086/261725

[9] S. D. Oliner and D. E. Sichel, "IT and Productivity: Where Are We Now and Where Are We Going?" Economic Review, Vol. 87, No. 3, 2002, pp. 15-44.

[10] D. B. Audretsch, "The Entrepreneurial Society," Oxford University Press, Oxford, 2007. doi:10.1093/acprof:oso/9780195183504.001.0001

[11] S. Moshiri and S. Nikpour, "International ICT Spillover," In: J. Steyn and G. Johanson, Eds., ICTs and Sustainable Solutions for the Digital Divide: Theory and Perspectives, Information Science Reference, 2010. doi:10.4018/978-1-61520-799-2.ch014

[12] A. E. DePrince, J. Ford and F. William, "A Primer on Internet Economics: Macro and Micro Impact of the Internet on the Economy," Business Economics, Vol. 34, No. 4, 1999, pp. 42-50.

[13] M. Granovetter, "The Impact of Social Structure on Economic Outcomes," The Journal of Economic Perspective, Vol. 19, No. 1, 2005, pp. 33-50. doi:10.1257/0895330053147958

[14] T. Parikh, N. Patel and Y. Schwartzman, "A Survey of Information Systems Reaching Small Producers in Global Agricultural Value Chains," International Proceedings of Conference on Information and Communication Tech- nologies and Development, Bangalore, 15-16 December 2007.

[15] S. Kalathil, "Dot.com for Dictators," Foreign Policy, Vol. 135, 2003, pp. 42-49. doi:10.2307/3183588

[16] D. Acemoglu, S. Johnson and J. A. Robinson, "The Colonial Origins of Comparative Development: An Empirical Investigation," The American Economic Review, Vol. 91, No. 5, 2001, pp. 1369-1401. doi:10.1257/aer.91.5.1369

[17] A. Davies and G. Quinlivan, "A Panel Data Analysis of the Impact of Trade on Human Development," The Journal of Socio-Economics, Vol. 35, No. 5, 2006, pp. 868876. doi:10.1016/j.socec.2005.11.048

[18] R. K. Goel and E. W. T. Hsieh, "Internet Growth and Economic Theory," Netnomics, Vol. 4, No. 2, 2002, pp. 221-225. doi:10.1023/A:1021225514442

[19] R. Jensen, "The Digital Provide: Information (Technology), Market Performance, and Welfare in the South Indian Fisheries Sector," Quarterly Journal of Economics, Vol. 122, No. 3, 2007, pp. 879-924. doi:10.1162/qjec.122.3.879

[20] P. Mishra and D. Newhouse, "Does Health Aid Matter?" Journal of Health Economics, Vol. 28, No. 4, 2009, pp. 855-872. doi:10.1016/j.jhealeco.2009.05.004 